\title{
Pemanfaatan Aplikasi Gamifikasi Wordwall Di Era Pandemi Covid-19 Untuk Meningkatkan Proses Pembelajaran Daring
}

\author{
Syahrizal Dwi Putra ${ }^{1}$; Diah Aryani ${ }^{2}$ Hani Dewi Ariessanti ${ }^{3}$ \\ 1,2,3 Universitas Esa Unggul \\ Program Studi Teknik Informatika, Fakultas Ilmu Komputer \\ ${ }^{1}$ syahrizal.dwi@esaunggul.ac.id \\ 2diah.aryani@esaunggul.ac.id \\ ${ }^{3}$ hani.dewi@esaunggul.ac.id
}

\begin{abstract}
Gamification applications for online learning are something that needs to be socialized at this time, especially during the pandemic to improve the learning process. SDIT Insan Rabbani / Integrated Islamic School (SIT) Insan Rabbani is an Islamic educational institution that is oriented towards character building for its students. To improve the online learning process in this pandemic era, the school wants to use the concept of gamification in the online learning process. Besides that, teachers also want ways to build school learning content that can increase student engagement for online learning, especially during the current pandemic. So the abdimas team provided a solution by offering counseling on the use of gamification using a wordwall. Wordwall was chosen so that teachers can easily understand the concept of gamification and create various quiz/evaluation templates that are owned by wordwall. The expected target is for teachers to understand concepts and use gamification to increase student involvement in the online learning process.
\end{abstract}

Keywords: gamification, online learning, wordwall

\begin{abstract}
ABSTRAK
Aplikasi gamifikasi untuk pembelajaran daring adalah suatu hal yang perlu disosialisasikan saat ini terutama di masa pandemi untuk meningkatkan proses pembelajaran. SDIT Insan Rabbani / Sekolah Islam Terpadu (SIT) Insan Rabbani merupakan lembaga pendidikan Islam yang berorientasi pada pembentukan karakter bagi peserta didiknya. Untuk meningkatkan proses pembelajaran daring di era pandemi ini, pihak sekolah menginginkan pemanfaatan dari konsep gamifikasi ke dalam proses pembelajaran daring. Disamping itu guru menginginkan pula cara membangun konten pembelajaran sekolah yang dapat meningkatkan keterlibatan murid untuk pembelajaran daring khususnya di masa pandemi saat ini. Maka tim abdimas memberikan solusi dengan menawarkan penyuluhan tentang pemanfaatan gamifikasi dengan menggunakan wordwall. Wordwall dipilih agar guru dapat dengan mudah memahami konsep gamifikasi dan membuat berbagai template quiz/evaluasi yang dimiliki oleh wordwall. Target yang diharapkan adalah agar guru dapat memahami konsep dan memanfaatkan gamifikasi untuk meningkatkan keterlibatan murid dalam proses pembelajaran daring.
\end{abstract}

Kata kunci: gamifikasi, pembelajaran daring, wordwall 


\section{PENDAHULUAN}

Kemajuan teknologi membutuhkan adaptasi dari setiap elemen dan efisiensi serta efektivitas kerja yang dapat ditingkatkan. Dengan pandemi COVID-19, persyaratan ini dipaksa untuk dipercepat lebih cepat. Di bidang pendidikan juga proses pembelajaran dalam bentuk pembelajaran jarak jauh harus menyesuaikan dengan kebutuhan tersebut dan mengembangkan produk media yang inovatif dan kontekstual sesuai dengan kebutuhan dan karakteristik peserta didik agar dapat belajar secara efektif dan menyenangkan [1].

Digitalisasi global membutuhkan perubahan di semua bidang kehidupan manusia, termasuk pendidikan. Tren modern mengarah pada pengenalan berbagai teknologi inovatif ke dalam proses pendidikan, termasuk diantaranya gamification (gamifikasi). Dalam konteks umum digitalisasi pendidikan, seorang calon guru harus memiliki keterampilan digital tertentu yang mendasari literasi digital untuk aktivitas profesionalnya [2]. Kemajuan ICT telah mengakibatkan perkembangan pesat industri game dimana guru kreatif merancang proses pembelajaran dan memanfaatkan berbagai macam gamifikasi. Gamifikasi adalah metode pengajaran yang menggunakan elemen permainan dengan tujuan memotivasi siswa untuk terlibat langsung dalam permainan dan pembelajaran pada saat yang bersamaan sehingga siswa mendapatkan pengalaman belajar yang menarik dan menyenangkan [3].Jadi gamifikasi dalam pembelajaran dan pendidikan merupakan aktivitas untuk memecahkan masalah yang berkaitan dengan pembelajaran dan pendidikan dengan menerapkan mekanisme permainan / game.

WordWall adalah aplikasi gamifikasi digital berbasis web yang menyediakan berbagai permainan dan kuis yang dapat digunakan pendidik untuk memberikan peringkat materi. Aplikasi ini dikembangkan oleh Visual Education Ltd, sebuah perusahaan Inggris. Aplikasi ini cocok untuk para pendidik yang ingin membuat metode penilaian pembelajaran. Hal yang paling menarik dari WordWall adalah bahwa game dapat dimainkan secara offline melalui alat cetak yang disediakan. Wordwall juga mendukung berbagi game di berbagai platform media sosial dan kode yang diembed [4]. Peningkatan yang signifikan dalam nilai kosakata siswa setelah menggunakan WordWall sebagai materi tambahan mempelajari kosakata. Ukuran efek yang ditunjukkan juga lebih besar mengenai efeknya di perilaku. Studi ini memberikan wawasan penting sebagai panduan bagi guru bahasa Inggris sekolah dasar dalam mengintegrasikan gamifikasi sebagai sarana pembelajaran untuk pembelajaran bahasa Inggris, khususnya dalam mengembangkan kemampuan kosakata bahasa Inggris siswa [5].

Kegiatan Belajar Dari Rumah (BDR) tidak menghambat guru untuk dapat menguasai berbagai macam teknologi dan berinovasi dengan memasukkan unsur permainan/game kedalam pembelajaran. Terdapat pengaruh aplikasi WordWall terhadap motivasi belajar siswa SD pada matapelajaran IPA. Siswa perlu dibiasakan belajar aktif dan tepat waktu dalam mengerjakan tugas dimasa pandemi ini. Ini adalah salah satu strategi guru yang dapat diterapkan agar anak termotivasi dalam belajar, sehingga tepat waktu untuk mengerjakan tugas dengan menggunakan aplikasi WordWall [6].

Permasalahan yang ada saat ini adalah keterbatasan sumber daya manusia atau pengajar yang memahami gamifikasi dan cara membuatnya di SDIT Insan Rabbani, sehingga menjadikan proses pembelajaran daring yang terjadi terasa monoton dan kurang komunikatif. Bagi siswa, tentu akan sangat sulit menggunakan beberapa aplikasi untuk mengikuti pembelajaran daring selama pandemi. Oleh karena itu, perlu diadakan penyuluhan dan bimbingan teknis kepada guru agar dapat memahami proses yang ada pada gamifikasi sehingga dapat diterapkan di SDIT Insan Rabbani. 


\section{METODE}

Kegiatan Pengabdian kepada Masyarakat berbentuk pelatihan dan penyuluhan mengenai pemanfaatan gamifikasi sebagai media pembelajaran dalam pembelajaran daring dengan metode penyampaian yang praktis melalui transfer ilmu dengan membuatkan video tutorial dan diskusi daring melalui video conference.

Adapun tahapan yang dilakukan adalah sebagai berikut:

1. Analisis Kebutuhan yaitu memahami beberapa karakteristik gamifikasi yang dapat digunakan untuk meningkatkan proses belajar dan mengajar secara daring.

2. Perencanaan yaitu mempersiapkan materi atau modul pelatihan beserta video tutorial yang akan digunakan saat berinteraksi dengan gamifikasi.

3. Pelaksanaan yaitu melakukan pembuatan gamifikasi yang dipilih dalam proses belajar dan mengajar secara daring dengan memanfaatkan video tutorial yang telah disediakan dan juga bimbingan teknis dan tanya jawab melalui video conference (zoom)

4. Evaluasi Pelatihan dilakukan dengan menyebarkan kuisioner kepada peserta pelatihan untuk mendapatkan umpan balik dari pelatihan yang sudah dilaksanakan.

5. Praktek Mandiri yaitu aktifitas dari masing-masing guru untuk mengerjakan contoh pemanfaatan gamifikasi dengan menggunakan aplikasi WordWall untuk matapelajaran yang diampunya serta memberikan bimbingan dan konsultasi dimana selama kegiatan pelatihan dan praktek mandiri secara daring melalui group whatsapp.

\section{HASIL DAN PEMBAHASAN}

Sebelum pelaksanaan kepada masyarakat, tim abdimas melakukan wawancara dengan Kepala Sekolah. Pada pembicaraan tersebut, kepala sekolah meminta untuk memberikan pelatihan yang berhubungan dengan gamifikasi bagi guru yang ada di SDIT Insan Rabbani untuk menunjang pembelajaran daring yang saat ini sedang berlangsung. Dari hasil diskusi tersebut, kami memutuskan bentuk kegiatan abdimas dengan penyuluhan dan pelatihan daring yang langsung dapat di lakukan olah guru agar dapat memahami gamifikasi.

Materi pelatihan yang disepakati dan sesuai dengan kebutuhan dari guru SDIT Insan Rabbani yaitu pengenalan dan penggunaan gamifikasi dengan wordwall. Selain itu point penting lainnya dari observasi tersebut adalah penentuan waktu dan tempat pelatihan. Karena masih dalam situasi pandemi COVID-19, maka kami mengusulkan agar pelatihan dapat di lakukan melalui video conference (Zoom).

\subsection{Saat Pelatihan}

Kegiatan ini berlangsung pada saat terjadi pandemi COVID-19, sehingga pelaksanaan dilakukan dengan cara daring melalui video conference (zoom). Sebelum dilaksanakan pelatihan, tim menginformasikan undangan kepada Kepala Sekolah SDIT Insan Rabbani untuk disampaikan kepada para guru. Dan pada saat kegiatan para guru melakukan pendaftaran daring sesuai link yang diberikan termasuk juga link zoom untuk kegiatan pelatihan. Berikut URLnya, Meeting ID: 8727527 9026 dan Password: dqT7K6: https://us02web.zoom.us/j/87275279026?pwd=R09Pd1BNSUVQUHJNUzJlcjlDbWxmZz

Pada sesi pemaparan materi pelatihan dalam kegiatan abdimas ini dimulai dengan melakukan test awal pemahaman peserta terhadap materi yang akan disampaikan dengan mencoba bertanya langsung kepada masing-masing guru yang ikut dalam pelatihan tersebut. Beberapa peserta banyak yang belum mendengar tentang konsep gamifikasi dan juga belum mengetahui dan menggunakan 
aplikasi gamifikasi WordWall.

Pada awal pemaparan materi, instruktur terlebih dahulu memberikan link hasil dari penggunaan aplikasi WordWall yang berada pada situs www.wordwall.net agar para peserta dapat merasakan bagaimana penggunaan WordWall tersebut dalam proses pembelajaran. Setelah itu, instruktur menjelaskan tentang pemanfaatan gamifikasi untuk pembelajaran daring yang dapat meningkatkan keterlibatan siswa. WordWall sangat mudah dipahami bagi pemula dan memiliki desain yang sederhana dan dapat memudahkan peserta/user baru dalam memahami fitur dan template pada aplikasi WordWall. Selain hal itu diberikan pula tahapan - tahapan dalam membangun aktivitas pembelajaran dan membagikan hasil aktivitas dan konten permainan/pembelajaran yang sudah dibuat ke siswa.

Berikut salah satu tampilan presentasi yang dilakukan saat pemaparan materi melalui video conference (zoom).

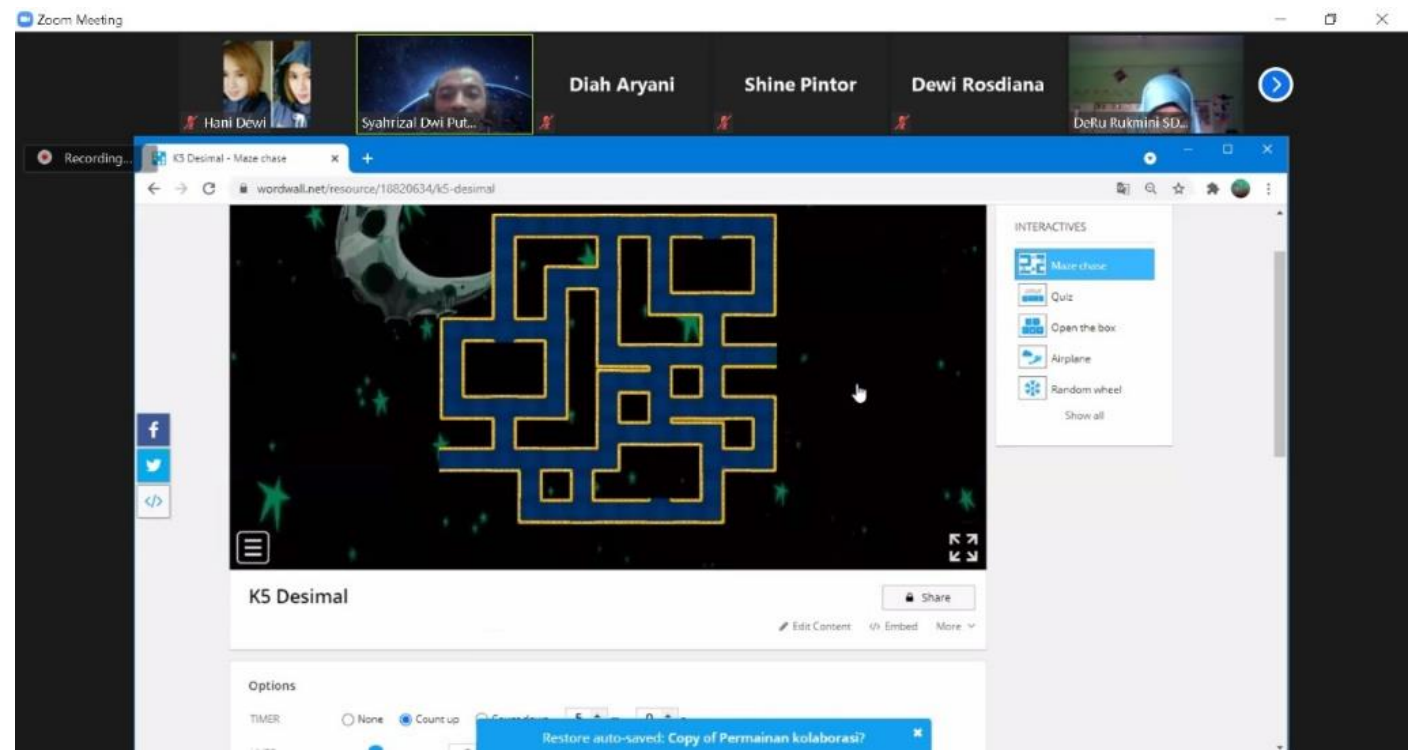

Gambar 1. Pemaparan Pelatihan Daring melalui Zoom

\section{PEMANFAATAN GAMIFIKASI PADA PEMBELAJARAN DARING DI ERA PANDEMI MENGGUNAKAN WORDWALL}
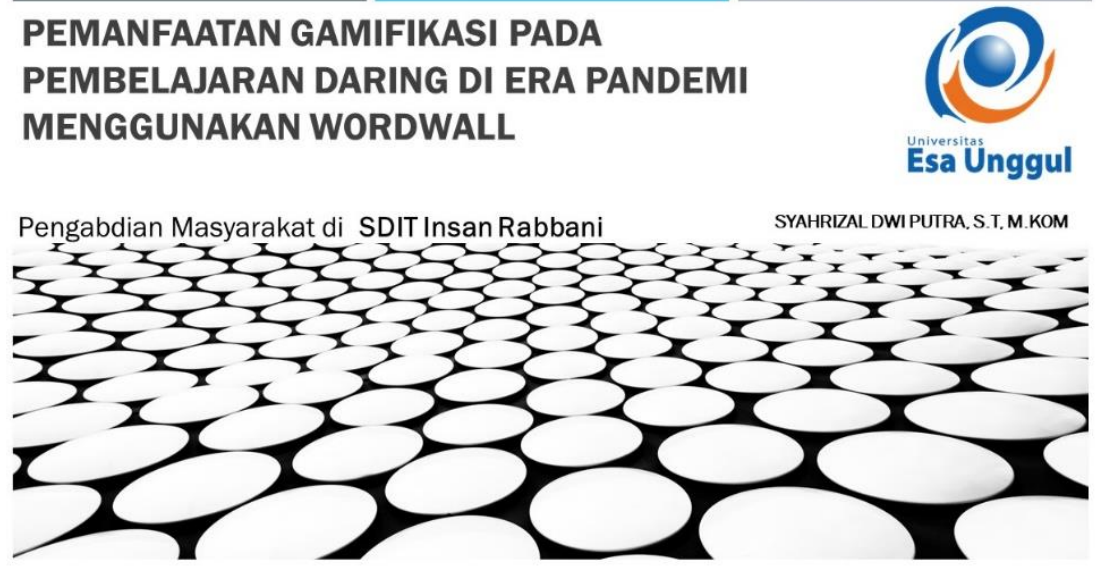


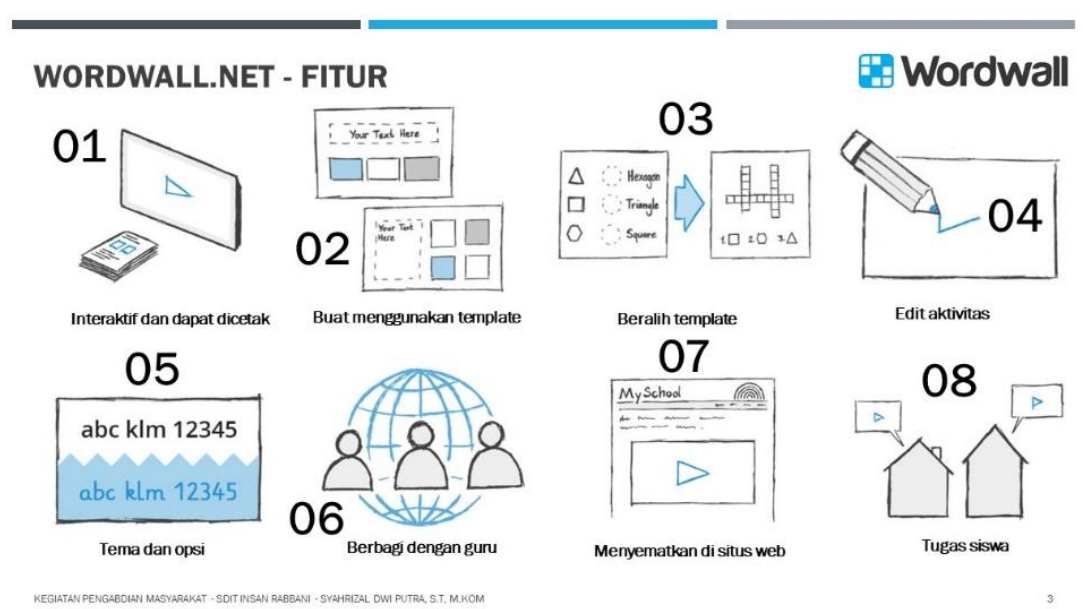

Gambar 2. Materi Pelatihan Daring Aplikasi WordWall

Pada sesi tanya jawab, peserta terlihat sangat antusias mendalami menggunakan aplikasi WordWall dan contoh penerapannya pada masing-masing mata pelajaran yang diajarkan oleh guru tersebut. Banyak peserta/guru yang ternyata baru mengetahui bahwa dengan menggunakan WordWall tidak perlu menginstall apapun dalam laptop atau handphone/smartphone, sebagaimana tidak membutuhkan ruang penyimpaan yang besar. Para peserta/guru tertarik untuk menggunakan aplikasi gamifikasi WordWall karena hanya butuh koneksi internet untuk dapat langsung menggunakan aplikasi tersebut

Diskusi berlanjut tentang fitur-fitur yang dimiliki oleh WordWall. Salah satunya adalah pengaturan waktu, nyawa, tingkat kesulitan dan apakah jawaban dimunculkan setelah game selesai dimainkan. Dijelaskan pula bagaimana menampilkan fitur papan rangking yang akan merangking skor dan waktunya.

\subsection{Evaluasi Pelatihan}

Setelah pelaksanaan kegiatan pelatihan secara daring dengan tema gamifikasi dengan aplikasi WordWall, maka diberikan kuisioner kepada para peserta/guru yang bertujuan untuk mengetahui tingkat pemahaman dan ketertarikan peserta/guru SDIT Insan Rabbani terhadap kesiapan penggunaan media pembelajaran berbasis gamifikasi yang salah satunya menggunakan WordWall. Kuisioner terdiri dari 5 pertanyaan dengan jumlah 25 responden/guru sebanyak 25 orang. Data pengetahuan peserta tentang konsep gamifikasi dan WordWall dijelaskan pada gambar berikut :

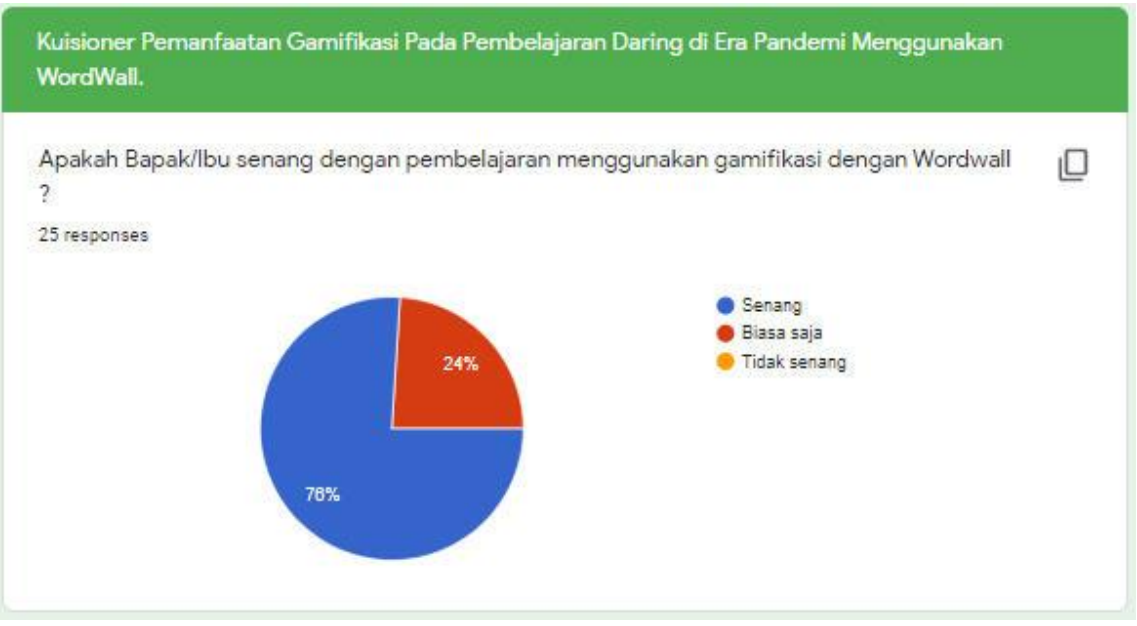


Wordwall membantu saya untuk membuat soal dengan mudah, menarik dan interaktif.

25 responses

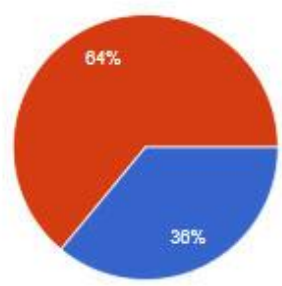

- Sangat Setuju

Tidak Setuju

Wordwall dapat digunakan dalam penilaian proses belajar dan hasil belajar peserta didik.

25 responses

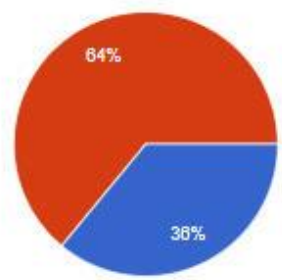

- Sangat Setuju

Setuju

Tidak Setuju

Program pengabdian kepada masyarakat ini sudah sesuai dengan kebutuhan Bapak/lbu dalam pembelajaran daring.

25 responses

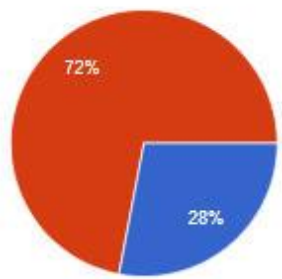

- Sangat Setuju

Setuju

Tidak Setuju

Bapak/lbu menerima dan mengharapkan program pengabdian masyarakat saat ini dan masa yang akan datang.

25 responses

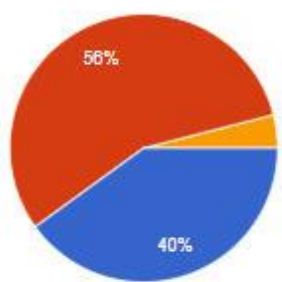

Gambar 3. Hasil Survey Kuisioner Pelatihan Daring Gamifikasi dengan WordWall

\subsection{Praktek Mandiri}

Setelah pelaksanaan pelatihan dan tutorial penggunaan aplikasi WordWall dari instruktur selesai, maka dilanjutkan dengan praktek mndiri. Pada praktek mandiri ini, peserta diberikan materi berupa video praktek dan juga file tutorial penggunaan WordWall yang bertujuan agar peserta dapat 
melanjutkan pemahaman tentang konsep gamifikasi dan mengimplementasikannya dengan menggunakan WordWall secara mandiri.

Para peserta pelatihan diberikan tugas praktek mandiri untuk membuat satu konten permainan/pembelajaran yang sesuai dengan mata pelajaran yang diajarkan dan link hasil dari praktek mandirinya dikirimkan kepada instruktur untuk diberi penilaian dan umpan balik. Berdasarkan data hasil penugasan yang dikerjakan oleh para peserta pelatihan, maka hasil analisis terhadap praktek mandiri terdapat pada tabel berikut:

Tabel 1. Analisa Hasil Penugasan

\begin{tabular}{ll}
\hline \multicolumn{1}{c}{ Bentuk Penugasan } & \multicolumn{1}{c}{ Analisis Hasil Penugasan } \\
\hline $\begin{array}{l}\text { Mendaftar di situs wordwall.net } \\
\text { sebagai guru }\end{array}$ & $\begin{array}{l}\text { Seluruh peserta dapat memiliki akun di wordwall.net } \\
\text { sebagai guru }\end{array}$ \\
\hline Membuat aktivitas & $\begin{array}{l}\text { Seluruh peserta mampu membuat aktivitas } \\
\text { pembelajaran }\end{array}$ \\
\hline Memilih dan berganti template & $\begin{array}{l}\text { Seluruh peserta dapat memilih template aktivitas dan } \\
\text { mengganti template aktivitas yang sudah ada } \\
\text { sebelumnya. }\end{array}$ \\
\hline $\begin{array}{l}\text { Membuat konten permainan / kuis } \\
\text { Memberikan setting pengaturan }\end{array}$ & $\begin{array}{l}\text { Seluruh peserta dapat membuat konten permainan / } \\
\text { kuis sesuai dengan template yang dipilihnya }\end{array}$ \\
$\begin{array}{l}\text { waktu, nyawa, tingkat kesulitan dan } \\
\text { apakah jawaban dimunculkan setelah } \\
\text { game selesai }\end{array}$ & $\begin{array}{l}\text { waktu, nyawa, tingkat kesulitan dan memunculkan } \\
\text { jawan setelah game selesai }\end{array}$ \\
\hline $\begin{array}{l}\text { Membagikan/share } \\
\text { kepada siswa }\end{array}$ & permainan \\
\hline
\end{tabular}

\section{KESIMPULAN}

Pelaksanaan kegiatan pengabdian masyarakat yang dilakukan dengan pelatihan daring tentang gamifikasi dan penerapan aplikasi WordWall di SDIT Insan Rabbani berjalan dengan baik dan lancar. Peserta pelatihan yang terdiri atas 25 peserta sangat merespon pelatihan tersebut. Dari hasil evaluasi serta temuan-temuan yang diperoleh selama pelaksanaan kegiatan pengabdian masyarakat ini, dapat disimpulkan bahwa program pelatihan ini telah mampu memberikan manfaat yang sangat besar dan tepat sasaran bagi para guru SDIT Insan Rabbani dan sesuai dengan kebutuhan guru saat pandemi.

Hasil kuisioner menunjukkan $70 \%$ peserta senang dengan pembelajaran menggunakan gamifikasi dengan WordWall. 36\% peserta sangat setuju dan 64\% peserta setuju WordWall membantu dalam membuat soal dengan mudah, menarik dan interaktif dan dapat digunakan dalam penilaian proses belajar dan hasil belajar peserta didik. Guru sangat antusias dalam mengikuti pelatihan aplikasi WordWall ini dan berharap dapat menerapkan WordWall dalam pembelajaran daring pada SDIT Insan Rabbani di era pandemi ini.

\section{SARAN}

Program pengabdian masyarakat seperti ini bisa dilaksanakan secara reguler dan berkala, karena pemanfaatan aplikasi gamifikasi dalam pembelajaran daring di era pandemi ini sangat dibutuhkan oleh banyak sekolah. Selain itu perlu materi gamifikasi yang diangkat selain dari aplikasi WordWall, agar guru dapat memiliki banyak pilihan dalam menerapkan strategi pembelajarannya dengan menggunakan gamifikasi. 


\section{UCAPAN TERIMA KASIH}

Kami mengucapkan terima kasih kepada Kepala Sekolah SDIT Insan Rabbani dan Universitas Esa Unggul yang telah memberi dukungan yang membantu pelaksanaan kegiatan pengabdian pada masyarakat sehingga pelatihan daring tentang gamifikasi dengan menggunakan aplikasi WordWall ini berjalan sesuai yang diharapkan dan lancar.

\section{DAFTAR PUSTAKA}

[1] J. Shiddiq, "INOVASI PEMANFAATAN WORD-WALL SEBAGAI MEDIA GAMEBASED LEARNING UNTUK BAHASA ARAB," Journal of Applied Linguistic and Islamic Education (JALIE), vol. 5, no. 1, pp. 151-168, 2021.

[2] S. Desnenko, T. Pakhomova, S. Starostina and J. Tokareva, "Gamification in the formation of digital skills of future teachers," in International Scientific and Practical Conference "State and Prospects for the Development of Agribusiness - INTERAGROMASH 2021", Russia, 2021.

[3] B. Krisbiantoro, "The effectiveness of gamification to enhance students' mastery on tenses viewed from students' creativity," Journal of Advanced Multidisciplinary Research (JAMR), vol. 1, no. 2, pp. 73-97, 2020.

[4] Y. Khairunisa, "PEMANFAATAN FITUR GAMIFIKASI DARING MAZE CHASEWORDWALL SEBAGAI MEDIA PEMBELAJARAN DIGITAL MATA KULIAH STATISTIKA DAN PROBABILITAS," MEDIASI - Jurnal Kajian dan Terapan Media, Bahasa, Komunikasi, vol. 2, no. 1, pp. 41-47, 2021.

[5] S. Hasram, M. K. M. Nasir, M. Mohamad, M. Y. Daud, M. J. A. Rahman and W. M. R. Wan Mohammad, "The Effects of WordWall Online Games (WOW) on English Language Vocabulary Learning Among Year 5 Pupils," Theory and Practice in Language Studies, vol. 11, no. 9, pp. 1059-1066, 2021.

[6] P. Gandasari and P. Pramudiani, "Pengaruh Aplikasi Wordwall terhadap Motivasi Belajar IPA Siswa di Sekolah Dasar," EDUKATIF: JURNAL ILMU PENDIDIKAN, vol. 3, no. 6, pp. 3689 - 3696, 2021. 